\title{
BMJ Open Risk of bladder cancer in patients with diabetes: a retrospective cohort study
}

\author{
Maria E Goossens, ${ }^{1}$ Maurice P Zeegers, ${ }^{2}$ Marloes T Bazelier, ${ }^{3}$ Marie L De Bruin, ${ }^{3}$ \\ Frank Buntinx, ${ }^{1,4}$ Frank de Vries ${ }^{3,5,6,7}$
}

To cite: Goossens ME, Zeegers MP, Bazelier MT, et al. Risk of bladder cancer in patients with diabetes: a retrospective cohort study. BMJ Open 2015;5:e007470. doi:10.1136/bmjopen-2014007470

- Prepublication history for this paper is available online. To view these files please visit the journal online (http://dx.doi.org/10.1136/ bmjopen-2014-007470)

Received 18 December 2014 Revised 14 April 2015 Accepted 29 April 2015
CrossMark

For numbered affiliations see end of article.

Correspondence to

Frank de Vries;

f.devries@uu.nl

\section{ABSTRACT}

Objective: The objective of this study was to examine the association between diabetes, and both urinary bladder cancer (UBC) risk and mortality.

Methods: We conducted a retrospective cohort study using data from the UK Clinical Practice Research Datalink (CPRD) linked to the Office of National Statistics (ONS). Patients diagnosed with diabetes mellitus type 1 or 2 , or using antidiabetic drugs (ADDs), were compared to matched non-diabetic controls. Cox proportional hazards models were used to estimate the risk and mortality of UBC. We adjusted for age, sex, smoking status and body mass index.

Results: The cohort included 329168 patients using ADD, and 307315 controls with 1295 and 1071 patients, respectively, diagnosed as having UBC during follow-up. The adjusted HRs of UBC were 0.77 (95\% $\mathrm{Cl} 0.57$ to 1.05$)$ and $1.04(95 \% \mathrm{Cl} 0.96$ to 1.14$)$ for type 1 and 2 diabetes, respectively. These results were similar if we restricted our analysis to an inception cohort. We noticed a small increased risk during the first year after diagnosis (HR=1.26 $(95 \% \mathrm{Cl} 1.05$ to $1.52)$ ), which could be explained by detection bias. There was no influence of the severity of diabetes as measured by the glycated haemoglobin. Mortality of UBC was not increased for patients with either type 1 ( $\mathrm{HR}=0.95(95 \% \mathrm{Cl} 0.39$ to 2.34$)$ ) or type 2 diabetes (HR=1.16 (95\% Cl 0.91 to 1.46$)$ ).

Conclusions: Neither the risk of UBC nor the mortality from UBC was increased in patients with type 1 and patients with type 2 diabetes in the CPRD data.

\section{BACKGROUND}

The global 2013 estimate of diabetes mellitus prevalence among adults (aged 20-79 years) was $8.3 \%$, affecting 382 million adults in the world and $6.6 \%$ in the UK. ${ }^{1}$ Between 2010 and 2030, the number of adults with diabetes in developing countries is expected to increase by $69 \%$, and by $20 \%$ in developed countries. $^{2}{ }^{3}$ In 2012, more than 400000 cases of urinary bladder cancer (UBC) occurred worldwide, making it the seventh most common type of cancer. ${ }^{4}$ It is more frequent in men than in women, and age is now widely accepted as the greatest single

\section{Strengths and limitations of this study}

The Clinical Practice Research Datalink (CPRD) is a large population-based cohort representative of the total UK population.

- Detailed longitudinal information on drug prescription is available within the CPRD, and $95 \%$ and $80 \%$ of patients with type 1 and 2 diabetes, respectively, had received a formal diabetes diagnosis.

- Smoking status was available for all patients in our analysis.

- Detailed information about the cause of death is available for $44 \%$ of the patients by linking the patients to the Office of National Statistics (ONS) data.

- The effect of different antidiabetic drug medications is not considered in our analyses and this is a major limitation.

risk factor for developing UBC. Cigarette smoking and specific occupational exposures, such as carcinogenic dyes for painters and some genetic polymorphisms, are the other main known causes of UBC. ${ }^{5}$ Previous meta-analyses from cohort and case-control studies have shown an increased risk of UBC associated with type 2 diabetes with relative risks (RR) ranging from 1.11 (95\% CI 1.00 to 1.23 ) to 1.32 (95\% CI 1.18 to 1.49$){ }^{6-9}$ There is also evidence for a positive association between type 2 diabetes and mortality from UBC (RR=1.33 (95\% CI 1.14 to 1.55$)$. However, misclassification of type 1 and 2 diabetes was not excluded in these studies, because diagnostic codes were lacking and details about the diabetic history (duration, metabolic control) were not considered.

Two studies on type 1 diabetes reported an increased overall cancer incidence by $20 \%$, while the mechanisms remain unclear. ${ }^{10} 11$ The observed number of bladder cancer cases in these studies is very small, ranging from 4 to 27 cases. ${ }^{10-12}$ The objective of this study was to examine the association between diabetes mellitus, and both UBC risk and mortality, taking into account diabetes 
duration, metabolic control as expressed by glycated haemoglobin (HbAlc) and type of diabetes.

\section{METHODS}

\section{Data sources}

We conducted a retrospective cohort study using data from the UK Clinical Practice Research Datalink (CPRD) (January 1987-October 2013) linked to the Office of National Statistics (ONS) (January 1998-January 2012). The CPRD comprises prospectively collected computerised medical records of over 10 million patients under the care of more than 600 general practitioners (GPs) in the UK. The Read classification is used to enter medical diagnoses and procedures, and prescriptions are recorded based on the UK Prescription Pricing Authority Dictionary.

The recorded information on diagnoses and drug use was validated, and proved to be of high quality. ${ }^{13}$ The ONS provided data for the cause(s) of death and the exact date of death as recorded on death certificates by a registered medical practitioner attending to the patient during their last period.

\section{Study population}

All patients with at least one prescription of antidiabetic drugs (ADDs) (oral antidiabetic drugs (NIADs) and/or insulin) and aged above 18 years during the period of valid CPRD data collection were included. Each ADD user was matched to one control patient by year of birth, sex and practice. Controls could have any disease as long as they were non-diabetic patients at baseline and during follow-up. The date of the first ADD prescription defined the index date and controls were assigned the same index date as their matched ADD user. All participants with missing data for smoking status, a history of any cancer prior to the index date, except non-melanoma skin cancer, or a diagnosis of gestational diabetes or secondary diabetes ever during follow-up were excluded. All control patients who used diabetes treatment or had ever been diagnosed with type 1 or 2 diabetes ever during follow-up were excluded. All ADD users with diagnoses of type 1 and 2 diabetes were excluded as well, as were patients aged 30 years and older without a diagnosis of diabetes, who used insulin only at baseline. All study participants were followed up from the index date to either the end of data collection, the date of transfer of the patient out of the practice area, or the patient's death.

\section{Exposure}

Patients with type 1 diabetes were defined as those patients with a formal diagnosis of type 1 diabetes (as recorded in CPRD) or younger than 30 years and using insulin only at index date. Patients with type 2 diabetes were all patients with a formal diagnosis of type 2 diabetes (as recorded in CPRD) or using an oral ADD at index date. The total period of follow-up for each patient (patients with diabetes and unexposed controls) was divided into fixed time periods of 90 days. Age was determined at the start of each interval. The classification of type 1 and 2 diabetes, as well as sex, smoking status and body mass index (BMI), was determined at baseline. Diabetes duration was assessed in a timedependent manner by estimating the time since the date of the first ADD prescription (the index date). Diabetes control was assessed in a time-dependent manner using the most recent HbAlc record before the start of each time interval and within the previous year.

\section{Outcomes}

The primary outcome was UBC, as defined by Read codes, and was assessed in the complete CPRD study population (January 1987-October 2013). The secondary outcome was bladder cancer-related mortality as recorded on death certificates (International Classification of Diseases (ICD-10) categories C65, C67) and was assessed in the population eligible for linkage between CPRD and ONS data (44\% of the participants). The period of follow-up was restricted to the time that ONS data were available (January 1998-January 2012).

\section{Risk factors}

The major covariates of interest included age, sex, smoking status and BMI. Smoking status was characterised at baseline as current, former or lifelong non-smoker.

\section{Statistical analysis}

Analyses were conducted using Cox proportional hazards models with various subanalyses. As time scale we used time since first ADD use. We tested the proportional hazard assumption by comparing patients with diabetes to non-diabetes controls. The assumption was not violated. The first analysis compared the risk of UBC in ADD users with that in control patients to yield an estimate of the RR (as a HR) of UBC associated with ADD use. The calculations were adjusted for age, sex, smoking status and BMI. Results were stratified to type 1 and type 2 diabetes. A sensitivity analysis was performed excluding women with polycystic ovarian syndrome (PCOS). In a secondary analysis, risks were estimated for an inception cohort of ADD users using a 1-year lead-in time. The risk of UBC for patients with incident type 2 diabetic was further stratified by disease duration, sex and HbAlc. The risk of UBC mortality in ADD users compared with that of controls was assessed by Cox models as well and results were stratified by type of diabetes. All data management and statistical analyses were conducted using SAS V.9.1/9.2 software.

This study was approved by the Medicines and Healthcare products Authorities' Independent Scientific Advisory Committee, protocol number 13_050R.

\section{RESULTS}

After exclusion of all patients with a diagnosis of gestational diabetes (1983 and 154 for ADD users and 
controls, respectively), or secondary diabetes (485 and 70 for ADD users and controls, respectively), or cancer prior to index date (34955 and 34384 for ADD users and controls, respectively) or missing data for smoking status during follow-up (13 416 and 27558 for ADD users and controls, respectively), the study population consisted of 329168 patients with diabetes of whom $30823(9.4 \%)$ and $298345(90.6 \%)$ had type 1 and 2 diabetes, respectively, and 307315 controls. Patients diagnosed with type 1 and 2 diabetes at baseline (7614) and patients without diagnosis, using insulin only at baseline and 30 years or older (10 178), were not included in our analysis.

Table 1 shows baseline characteristics. The mean age at index date was 58 years. Forty-six per cent of the patients with diabetes had a BMI of 30 or above in contrast with $30 \%$ of the control participants.

During nearly 6 years of follow-up, 1071 patients of the control group and 1295 of the ADD users were diagnosed with bladder cancer. Patients with type 1 diabetes had no significantly lower risk of UBC $(\mathrm{HR}=0.77(95 \%$ CI 0.57 to 1.05$)$ ) than patients with type 2 diabetes $(\mathrm{HR}=1.04$ (95\% CI 0.96 to 1.14$)$ ) based on a Wald test $(p=0.054)$. The results for incident ADD users were similar (table 2).

For patients with incident type 2 diabetes, we noticed an increased risk of UBC (HR=1.26 (95\% CI 1.05 to 1.52)) during the first year after the first ADD prescription, compared to controls, which disappeared in subsequent years (table 3). Sixty per cent of the bladder cancers developed during the first 5 years after diabetes onset. There was no difference in UBC risk between male and female patients with type 2 diabetes (HR=1.11 (95\% CI 0.98 to 1.25$)$ and 1.01 (95\% CI 0.79 to 1.29 ), respectively). In patients with type 2 diabetes, there was no influence of HbAlc as an indicator of diabetes severity on UBC risk (table 4). UBC-related mortality was neither increased in patients with type 1 diabetes ( $\mathrm{HR}=0.79$ (95\% CI 0.32 to 1.94$)$ ) nor in patients with type 2 diabetes, compared to controls (HR=1.05 (95\% CI 0.83 to 1.33) ) (table 5).

Table 1 Baseline characteristics of antidiabetic drug (ADD) users and non-diabetic controls

\begin{tabular}{|c|c|c|c|c|}
\hline \multirow[b]{2}{*}{ Characteristics } & \multicolumn{2}{|l|}{ ADD users } & \multicolumn{2}{|l|}{ Controls } \\
\hline & $\mathrm{N}=329168$ & (Per cent) & 307315 & (Per cent) \\
\hline Follow-up time (years; mean) & 5.91 & & 5.66 & \\
\hline \multicolumn{5}{|l|}{ Sex } \\
\hline Female & 152683 & $(46.4)$ & 148791 & $(48.4)$ \\
\hline Male & 176485 & (53.6) & 158524 & (51.6) \\
\hline Age at index date (years; mean, median) & $58.6(60.0)$ & & $58.2(60.0)$ & \\
\hline $18-29$ & 19716 & $(6.0)$ & 19184 & $(6.2)$ \\
\hline 30-39 & 26236 & (8.0) & 28065 & $(9.1)$ \\
\hline $40-49$ & 43659 & (13.3) & 41539 & (13.5) \\
\hline $50-59$ & 68564 & (20.8) & 62400 & (20.3) \\
\hline $60-69$ & 80562 & $(24.5)$ & 71975 & (23.4) \\
\hline $70-79$ & 62064 & (18.9) & 56632 & $(18.4)$ \\
\hline $80+$ & 28367 & (8.6) & 27520 & $(9.0)$ \\
\hline \multicolumn{5}{|l|}{ Smoking status } \\
\hline Never smoker & 168832 & $(51.3)$ & 166190 & $(54.1)$ \\
\hline Current smoker & 66903 & (20.3) & 70765 & (23.0) \\
\hline Former smoker & 93433 & (28.4) & 70360 & (22.9) \\
\hline \multicolumn{5}{|l|}{ Body mass index $\left(\mathrm{kg} / \mathrm{m}^{2}\right)$} \\
\hline$<20.0$ & 6587 & $(2.0)$ & 16769 & $(5.5)$ \\
\hline 20.0-24.9 & 54212 & $(16.5)$ & 96636 & (31.4) \\
\hline 25.0-29.9 & 105547 & (32.1) & 103315 & (33.6) \\
\hline$\geq 30.0$ & 150152 & (45.6) & 55827 & (18.2) \\
\hline Unknown & 12670 & $(3.8)$ & 34768 & (11.3) \\
\hline \multicolumn{5}{|l|}{ ADD users } \\
\hline \multicolumn{5}{|l|}{ Formal diabetes diagnosis } \\
\hline Type 1 & 28964 & $(8.8)$ & & \\
\hline Type 2 & 239021 & $(72.6)$ & & \\
\hline \multicolumn{5}{|l|}{ No diabetes diagnosis } \\
\hline Insulin only at index date and $<30$ years & 1859 & $(0.6)$ & & \\
\hline Others & 59324 & $(18.0)$ & & \\
\hline \multicolumn{5}{|l|}{ Patients with diabetes } \\
\hline Type 1 diabetes* & 30823 & $(9.4)$ & & \\
\hline Type 2 diabetes $†$ & 298345 & $(90.6)$ & & \\
\hline
\end{tabular}


Table 2 Risk of bladder cancer in antidiabetic drug (ADD) users compared with controls, by type of diabetes and in incident ADD users

\begin{tabular}{|c|c|c|c|c|c|c|}
\hline \multirow[b]{2}{*}{ Exposure category } & \multicolumn{3}{|c|}{$\begin{array}{l}\text { ADD users }(\mathrm{N}=329168) \text { versus controls } \\
(\mathrm{N}=307315)\end{array}$} & \multicolumn{3}{|c|}{$\begin{array}{l}\text { Incident ADD users }(\mathrm{N}=179598) \text { versus } \\
\text { controls }(\mathrm{N}=233505)\end{array}$} \\
\hline & $\begin{array}{l}\text { Bladder } \\
\text { cancer } \\
\text { N (\%) }\end{array}$ & $\begin{array}{l}\text { Age-sex adj } \\
\mathrm{HR}(95 \% \mathrm{Cl})\end{array}$ & $\begin{array}{l}\text { Fully adj HR* } \\
(95 \% \mathrm{CI})\end{array}$ & $\begin{array}{l}\text { Bladder } \\
\text { cancer } \\
\mathrm{N}(\%)\end{array}$ & $\begin{array}{l}\text { Age-sex adj } \\
\text { HR }(95 \% \mathrm{Cl})\end{array}$ & $\begin{array}{l}\text { Fully adj HR* } \\
(95 \% \mathrm{Cl})\end{array}$ \\
\hline Controls & $1071(0.3)$ & 1 & 1 & $732(0.3)$ & 1 & 1 \\
\hline ADD users & $1295(0.4)$ & 1.09 (1.00 to 1.18$)$ & 1.03 (0.95 to 1.12$)$ & $746(0.4)$ & 1.15 (1.04 to 1.27$)$ & $1.08(0.97$ to 1.20$)$ \\
\hline Type 1 diabetes $†$ & $44(0.0)$ & 0.76 (0.56 to 1.02$) \S$ & 0.77 (0.57 to 1.05$)$ & $5(0.0)$ & 0.65 (0.27 to 1.58$)$ & $0.65(0.27$ to 1.57$)$ \\
\hline Type 2 diabetes $\ddagger$ & $1251(0.4)$ & $1.10(1.02$ to 1.20$)$ & $1.04(0.96$ to 1.14$)$ & $741(0.4)$ & 1.15 (1.04 to 1.28$)$ & $1.09(0.97$ to 1.21$)$ \\
\hline
\end{tabular}

\section{DISCUSSION}

We could not detect a significantly increased risk of UBC nor of increased mortality due to UBC in patients with type 1 and 2 diabetes compared to controls even if we reduced our cohort to incident ADD users. However, we noticed an increased risk of UBC in patients with type 2 diabetes during the first year after diagnosis. Diabetes control, as expressed by HbA1c, had no influence on the UBC risk in patients with type 2 diabetes.

Previous meta-analyses reported an increased risk. ${ }^{6-9}$ Even when these meta-analyses ${ }^{6-8}$ were restricted to studies that adjusted for smoking, there was still an increased RR ranging from 1.32 (95\% CI 1.18 to 1.49 ) to 1.48 (95\% CI 1.25 to 1.77 ), comparable to our RR for type 2 diabetes. On the other hand, in several studies, diabetes ascertainment was based on self-reporting. ${ }^{8}$ Those studies had an RR of 1.34 (95\% CI 1.11 to 1.62).
The increased risk of UBC in patients with diabetes decreased and significance disappeared when diabetes was asserted by other methods ( $R R=1.11 \quad(95 \%$ CI 0.95 to 1.31)). Furthermore, not all studies distinguished between diabetes type 1 and 2. Most of the studies excluded type 1 diabetes as a diagnosis of diabetes before 30 years of age. ${ }^{7}$ Subgroup analysis of studies restricted to Europe did not show an increased risk of UBC in patients with type 2 diabetes. ${ }^{6-8}$ Hence, our results are in line with those of European studies. ${ }^{12}$ 14-21 It is not clear why there is a difference between European studies and those of other regions.

We did not find an increased risk of bladder cancer in diabetes type 1 , which is in line with the results found in Sweden ${ }^{10} 11$ and in the UK. ${ }^{12}$

An increased risk of UBC during the first year after diabetes diagnosis was found in several other

Table 3 Risk of bladder cancer in incident patients with type 2 diabetes mellitus compared with controls, by duration of disease and sex

\begin{tabular}{|c|c|c|c|}
\hline \multirow[b]{2}{*}{ Exposure category } & \multicolumn{3}{|c|}{ Type 2 diabetes $(\mathrm{N}=175083$ ) versus controls $(\mathrm{N}=233505)$} \\
\hline & $\begin{array}{l}\text { Bladder cancer } \\
\mathrm{N}(\%)\end{array}$ & $\begin{array}{l}\text { Age-sex adj HR } \\
(95 \% \mathrm{Cl})\end{array}$ & $\begin{array}{l}\text { Fully adj HR* } \\
(95 \% \mathrm{Cl})\end{array}$ \\
\hline Controls & $732(0.3)$ & 1 & 1 \\
\hline Type 2 diabetes & $741(0.4)$ & $1.15(1.04$ to 1.28$)$ & 1.09 (0.97 to 1.21$)$ \\
\hline \multicolumn{4}{|c|}{ Duration of disease (years) $\dagger$} \\
\hline$<1$ & $149(0.1)$ & $1.34(1.12$ to 1.61$)$ & 1.26 (1.05 to 1.52$)$ \\
\hline $1-<2$ & $95(0.1)$ & $1.17(0.95$ to 1.45$)$ & $1.10(0.88$ to 1.37$)$ \\
\hline $2-<5$ & $201(0.1)$ & $1.02(0.87$ to 1.19$)$ & 0.95 (0.81 to 1.12$)$ \\
\hline $5-<10$ & $224(0.1)$ & $1.22(1.05$ to 1.41$)$ & $1.14(0.98$ to 1.33$)$ \\
\hline $10-<15$ & $67(0.0)$ & $1.19(0.93$ to 1.54$)$ & 1.14 (0.88 to 1.47$)$ \\
\hline$\geq 15$ & $5(0.0)$ & 0.43 (0.18 to 1.04$)$ & 0.42 (0.18 to 1.02$)$ \\
\hline \multicolumn{4}{|l|}{ Sex } \\
\hline Male‡ & $604(0.3)$ & 1.19 (1.06 to 1.33$)$ & 1.11 (0.98 to 1.25$)$ \\
\hline Female§ & $137(0.1)$ & $1.03(0.82$ to 1.29$)$ & 1.01 (0.79 to 1.29$)$ \\
\hline
\end{tabular}


Table 4 Risk of urinary bladder cancer in patients with type 2 diabetes mellitus by $\mathrm{HbA} 1 \mathrm{c}$ level at most recent measurement

\begin{tabular}{|c|c|c|c|}
\hline \multirow[b]{2}{*}{ Exposure category } & \multicolumn{3}{|c|}{ Patients with type 2 diabetes $(\mathrm{N}=298$ 345) } \\
\hline & $\begin{array}{l}\text { Bladder cancer } \\
\text { N (\%) }\end{array}$ & $\begin{array}{l}\text { Age-sex adj HR } \\
(95 \% \mathrm{Cl})\end{array}$ & $\begin{array}{l}\text { Fully adjusted HR* } \\
(95 \% \mathrm{Cl})\end{array}$ \\
\hline Type 2 diabetes & $1251(0.4)$ & & \\
\hline \multicolumn{4}{|l|}{ HbA1C level† } \\
\hline $\mathrm{HbA} 1 \mathrm{c}<6 \%$ & $57(0.0)$ & 1 & 1 \\
\hline $6 \leq \mathrm{HbA} 1 \mathrm{c}<7.0 \%$ & $278(0.1)$ & $1.18(0.89-1.57)$ & $1.19(0.90-1.58)$ \\
\hline $7 \leq \mathrm{HbA} 1 \mathrm{c}<8.0 \%$ & $248(0.1)$ & $1.16(0.87-1.55)$ & $1.18(0.89-1.58)$ \\
\hline $8 \leq \mathrm{HbA} 1 \mathrm{c}<9.0 \%$ & $110(0.0)$ & $1.09(0.79-1.50)$ & $1.10(0.80-1.52)$ \\
\hline $\mathrm{HbA} 1 \mathrm{c} \geq 9.0 \%$ & $106(0.0)$ & $1.17(0.85-1.62)$ & $1.17(0.85-1.62)$ \\
\hline Missing & $452(0.2)$ & $0.91(0.68-1.20)$ & $0.92(0.69-1.21)$ \\
\hline
\end{tabular}

studies. $^{20}{ }^{22-24}$ Likewise, for colorectal, lung, breast, liver, cervical, endometrial, ovarian, pancreatic and prostate cancers, a significantly increased risk was found within the months following diabetes onset. ${ }^{10} 2526$ This most likely indicates the presence of a detection bias, in the sense that the diagnosis of diabetes leads to increased medical attention, and thus to earlier detection of any present but undiagnosed cancer. This phenomenon has also been observed immediately after the diagnosis of prostate cancer. The incidence of UBC was 18 times higher in patients with prostate cancer due to diagnostic bias. $^{27} 28$ On the other hand, in contrast with some other studies, we could not confirm the hypothesis that fewer physician visits in the year before diabetes diagnosis increases the risk of bladder cancer diagnosis in contrast with some other studies. ${ }^{24}$ Apart from the increased risk of UBC during the first year of diabetes diagnosis, possibly due to detection bias, we did not find an association between diabetes duration and developing bladder cancer. Seeing that nearly $50 \%$ of the patients had a follow-up of more than 5 years and only $40 \%$ of the bladder cancers were diagnosed after these 5 years, while only $10 \%$ was diagnosed after 10 years, we can conclude that having diabetes for more than 5 years did not alter the risk of UBC.

Our finding of no association between HbAlc and cancer risk is consistent with the results of a recent meta-analysis of major randomised controlled trials. ${ }^{29}$
The strength of this study was that the CPRD is a large population-based cohort, representative of the total UK population. Type 2 diabetes accounts for $85 \%$ to $95 \%$ of all diabetes in high-income countries. ${ }^{1}$ In the UK, $10 \%$ of the people with diabetes have type $1,{ }^{30}$ which was confirmed in our analysis $(9.4 \%)$. We had detailed longitudinal information on drug prescription, and $95 \%$ and $80 \%$ of the patients with type 1 and 2 diabetes, respectively, had received a formal diabetes diagnosis. Patients with type 1 and 2 diabetes at baseline, and patients without diagnosis, using insulin only at baseline and 30 years or older, were excluded from our analysis. Consulting rates for diabetes in the CPRD have been compared with equivalent data from the fourth National Morbidity Survey in General Practice, confirming the validity of the morbidity data in the CPRD. ${ }^{31}$ Furthermore, since 2004, GPs have been stimulated to provide 'quality care' by the Quality and Outcomes Framework (QOF). The UK has a National Service Framework for Diabetes (NSF). ${ }^{32}$ Guidelines to be followed by the GPs are outlined in the guideline for type $1^{33}$ and 2 diabetes ${ }^{34}$ of the National Institute of Health and Care Excellence (NICE). For diagnosis, the NICE guideline refers to the International Diabetes Federation (IDF) Diabetes Atlas. ${ }^{1}$ Diagnosis of diabetes is directly linked with prescription of ADD whereas Impaired Glucose Tolerance (IGT) is referred to as people whose blood glucose levels are high but not as high as those in people with diabetes. Our

Table 5 Risk of urinary bladder cancer (UBC) mortality in antidiabetic drug (ADD) users compared with controls, by type of diabetes mellitus

\begin{tabular}{|c|c|c|c|}
\hline \multirow[b]{2}{*}{ Exposure category } & \multicolumn{3}{|c|}{ ADD user ( $N=143566)$ versus controls $(N=114994)$} \\
\hline & $\begin{array}{l}\text { Bladder cancer } \\
\text { mortality } N(\%)\end{array}$ & $\begin{array}{l}\text { Age-sex adjusted } \\
\text { HR }(95 \% \mathrm{Cl})\end{array}$ & $\begin{array}{l}\text { Fully adjusted } \\
\mathrm{HR}^{\star}(95 \% \mathrm{Cl})\end{array}$ \\
\hline Controls & $145(0.1)$ & 1 & 1 \\
\hline ADD users & $179(0.1)$ & $1.04(0.83$ to 1.29$)$ & $1.04(0.83$ to 1.31$)$ \\
\hline Type 1 diabetes & $5(0.0)$ & $0.73(0.30$ to 1.79$)$ & $0.79(0.32$ to 1.94$)$ \\
\hline Type 2 diabetes & $174(0.1)$ & $1.05(0.84$ to 1.31$)$ & $1.05(0.83$ to 1.33$)$ \\
\hline
\end{tabular}


cohort was restricted to those patients receiving ADD. Furthermore, we had HbA1c values for 1251 of the 1295 patients with bladder cancer. So, $96 \%$ of the patients have additional proof of being diabetic.

Metformin can also be used to treat obesity or PCOS. We have no means to test the possible effect of metformin prescribed for obesity, although the clinical impression exists that such treatments tend to be relatively short. In our cohort, 12841 women were diagnosed with PCOS. None of them developed UBC. A sensitivity analysis, excluding those PCOS women, showed exactly the same HRs. Additionally, we have information on the smoking status of all patients who were included in our analysis, which is essential given that smoking is one of the major risk factors for bladder cancer. ${ }^{5}$ The link with the ONS data allowed us to have detailed information about the cause of death for $44 \%$ of patients.

The fact that the effect of different antidiabetic drug medications was not considered in our analyses is a major limitation. We are aware of the fact that metformin can have a protective effect on cancer ${ }^{335}$ and that pioglitazone could be associated with an increased risk of bladder cancer. ${ }^{36-40}$ This was, however, beyond the scope of this study.

With this study, and against the background of all previous research, the likelihood of a clinically relevant association between diabetes and UBC risk has become very limited. The influence of antidiabetic treatment on bladder cancer risk, however, is still contradictable and requires further study in the future.

\section{CONCLUSION}

Neither the risk of UBC nor the mortality from UBC was observed to be increased in patients with type 1 or type 2 diabetes in the CPRD data. Our results are in line with those of previous European studies.

\author{
Author affiliations \\ ${ }^{1}$ Department of General Practice, KU Leuven, Leuven, Belgium \\ ${ }^{2}$ Department of Complex Genetics, University of Maastricht, NUTRIM School \\ of Nutrition, Translational Research in Metabolism, Maastricht, \\ The Netherlands \\ ${ }^{3}$ Division of Pharmacoepidemiology and Clinical Pharmacology, Utrecht \\ University, Utrecht Institute of Pharmaceutical Sciences, The Netherlands \\ ${ }^{4}$ Department of General Practice, University of Maastricht, CAPHRI, School for \\ Primary Care and Public Health, Maastricht, The Netherlands \\ ${ }^{5}$ Department of Clinical Pharmacy and Toxicology, Maastricht University \\ Medical Centre, Maastricht, The Netherlands \\ ${ }^{6}$ Research Institute CAPHRI, University of Maastricht, The Netherlands \\ ${ }^{7}$ MRC Lifecourse Epidemiology Unit, University of Southampton, \\ Southampton, UK
}

Contributors MEG wrote the manuscript and researched data. MTB performed the statistical analysis and reviewed the manuscript. FB and MPZ reviewed/ edited the manuscript. FdV and MLDB provided the data and reviewed/edited the manuscript.

Funding The research leading to the results of this study received funding from the European Community's Seventh Framework Programme (FP-7) under grant agreement number 282526, the CARING project. The funding source had no role in study design, data collection, data analysis, data interpretation or writing of the report.
Competing interests The Department of Pharmacoepidemiology and Clinical Pharmacology employing authors MTB and FdV received unrestricted funding for pharmacoepidemiological research from GlaxoSmithKline, Novo Nordisk, the private-public-funded Top Institute Pharma (http://www.tipharma.nl; includes co-funding from universities, government and industry), the Dutch Medicines Evaluation Board and the Dutch Ministry of Health. The GPRD is owned by the UK Department of Health and operates within the Medicines and Healthcare Products Regulatory Agency (MHRA). GPRD is funded by the MHRA, Medical Research Council, various universities, contract research organisations and pharmaceutical companies. MLDB is employed by Utrecht University as a senior researcher conducting research in collaboration with the WHO Collaborating Centre for pharmaceutical policy and regulation. This Centre receives no direct funding or donations from private parties, including the pharma industry. Research funding from public-private partnerships, for example, IMI and TI Pharma (http://www.tipharma.nl), is accepted under the condition that no company-specific product or company related study is conducted. The Centre has received unrestricted research funding from public sources, for example, Netherlands Organization for Health Research and Development (ZonMW), the Dutch Health Care Insurance Board (CVZ), EU 7th Framework Program (FP7), Dutch Medicines Evaluation Board (MEB) and Dutch Ministry of Health.

Ethics approval Medicines and Healthcare products Authorities' Independent Scientific Advisory Committee.

Provenance and peer review Not commissioned; externally peer reviewed.

Data sharing statement CPRD data are available under license with the Medicines and Healthcare products Regulatory Agency (MHRA) in London, UK. The datasets that have been used for this project have been licensed by the MHRA. Access to datasets that have been used for this study are available for audit purposes only, conditional on permission by the MHRA.

Open Access This is an Open Access article distributed in accordance with the Creative Commons Attribution Non Commercial (CC BY-NC 4.0) license, which permits others to distribute, remix, adapt, build upon this work noncommercially, and license their derivative works on different terms, provided the original work is properly cited and the use is non-commercial. See: http:// creativecommons.org/licenses/by-nc/4.0/

\section{REFERENCES}

1. International Diabetes Federation. IDF diabetes atlas. 6th edn. Brussels, Belgium: International Diabetes Federation, 2013 http://www.idf.org/diabetesatlas

2. Shaw JE, Sicree RA, Zimmet PZ. Global estimates of the prevalence of diabetes for 2010 and 2030. Diabetes Res Clin Pract 2010;87:4-14

3. Ngwana G, Aerts M, Truyers C, et al. Relation between diabetes, metformin treatment and the occurrence of malignancies in a Belgian primary care setting. Diabetes Res Clin Pract 2012;97:331-6.

4. Ferlay J, Soerjomataram I, Ervik M, et al. GLOBOCAN 2012 v1.0, Cancer Incidence and Mortality Worldwide: IARC CancerBase No. 11 [Internet]. Lyon, France: International Agency for Research on Cancer, 2013. http://globocan.iarc.fr

5. Goossens ME, Buntinx F, Zeegers MP. Aetiology, demographics and risk factors for bladder cancer. In: The Oxford textbook of surgery. Oxford University Press (OUP). 2015, in press.

6. Larsson SC, Orsini N, Brismar K, et al. Diabetes mellitus and risk of bladder cancer: a meta-analysis. Diabetologia 2006;49:2819-23.

7. Zhu Z, Zhang X, Shen Z, et al. Diabetes mellitus and risk of bladder cancer: a meta-analysis of cohort studies. PLOS ONE 2013;8:e56662.

8. Xu X, Wu J, Mao Y, et al. Diabetes mellitus and risk of bladder cancer: a meta-analysis of cohort studies. PLOS ONE 2013;8: e58079.

9. Starup-Linde J, Karlstad O, Eriksen SA, et al. CARING (CAncer Risk and INsulin analoGues): the association of diabetes mellitus and cancer risk with focus on possible determinants-a systematic review and a meta-analysis. Curr Drug Saf 2013;8:296-332.

10. Shu X, Ji J, Li X, et al. Cancer risk among patients hospitalized for type 1 diabetes mellitus: a population-based cohort study in Sweden. Diabet Med 2010;27:791-7.

11. Zendehdel K, Nyren O, Ostenson CG, et al. Cancer incidence in patients with type 1 diabetes mellitus: a population-based cohort study in Sweden. J Natl Cancer Inst 2003;95:1797-800. 
12. Swerdlow AJ, Laing SP, Qiao Z, et al. Cancer incidence and mortality in patients with insulin-treated diabetes: a UK cohort study. Br J Cancer 2005;92:2070-5.

13. Herrett E, Thomas SL, Schoonen WM, et al. Validation and validity of diagnoses in the General Practice Research Database: a systematic review. Br J Clin Pharmacol 2010;69:4-14.

14. Adami HO, McLaughlin J, Ekbom A, et al. Cancer risk in patients with diabetes mellitus. Cancer Causes Control 1991;2:307-14.

15. La Vecchia C, Negri E, Franceschi S, et al. A case-control study of diabetes mellitus and cancer risk. Br J Cancer 1994;70:950-3.

16. Wideroff L, Gridley G, Mellemkjaer L, et al. Cancer incidence in a population-based cohort of patients hospitalized with diabetes mellitus in Denmark. J Natl Cancer Inst 1997;89:1360-5.

17. $\mathrm{Ng} \mathrm{Y}$, Husain I, Waterfall $\mathrm{N}$. Diabetes mellitus and bladder cancer-an epidemiological relationship? Pathol Oncol Res 2003;9:30-1.

18. Verlato G, Drane JW, Aldrich TE. Statistical methods for surveillance of diabetes events. Diabetes Nutr Metab 2003;16:198-200.

19. Larsson SC, Andersson SO, Johansson JE, et al. Diabetes mellitus, body size and bladder cancer risk in a prospective study of Swedish men. Eur J Cancer 2008;44:2655-60.

20. Ogunleye AA, Ogston SA, Morris AD, et al. A cohort study of the risk of cancer associated with type 2 diabetes. $\mathrm{Br} J$ Cancer 2009;101:1199-201.

21. Attner B, Landin-Olsson M, Lithman $T$, et al. Cancer among patients with diabetes, obesity and abnormal blood lipids: a population-based register study in Sweden. Cancer Causes Control 2012;23:769-77.

22. Hemminki K, Li X, Sundquist J, et al. Risk of cancer following hospitalization for type 2 diabetes. Oncologist 2010;15:548-55.

23. Atchison EA, Gridley G, Carreon JD, et al. Risk of cancer in a large cohort of U.S. veterans with diabetes. Int J Cancer 2011;128:635-43.

24. Colmers IN, Majumdar SR, Yasui Y, et al. Detection bias and overestimation of bladder cancer risk in type 2 diabetes: a matched cohort study. Diabetes Care 2013;36:3070-5.

25. Carstensen B, Witte DR, Friis S. Cancer occurrence in Danish diabetic patients: duration and insulin effects. Diabetologia 2012;55:948-58.
26. Johnson JA, Bowker SL, Richardson K, et al. Time-varying incidence of cancer after the onset of type 2 diabetes: evidence of potential detection bias. Diabetologia 2011;54:2263-71.

27. Kellen E, Zeegers MP, Dirx M, et al. Occurrence of both bladder and prostate cancer in five cancer registries in Belgium, The Netherlands and the United Kingdom. Eur J Cancer 2007;43:1694-700.

28. Kellen E, Zeegers MP, Joniau S, et al. Examining the co-occurrence of bladder and prostate cancer: a worthwhile investigation? Future Oncol 2007;3:515-19.

29. Johnson JA, Bowker SL. Intensive glycaemic control and cancer risk in type 2 diabetes: a meta-analysis of major trials. Diabetologia 2011;54:25-31.

30. Diabetes in the UK. Key statistics on diabetes, 2012.

31. Hollowell J. The general practice research database: quality of morbidity data. Popul Trends 1997:36-40.

32. National Service Framework for Diabetes. Department of Health. 2001.

33. Type 1 diabetes|Guidance and guidelinesINICE. 2004. http://wwwniceorguk/guidance/cg15

34. Type 2 diabetes/Guidance and guidelinesINICE. 2009. http://wwwniceorguk/guidance/cg87

35. Peeters PJ, Bazelier MT, Vestergaard P, et al. Use of metformin and survival of diabetic women with breast cancer. Curr Drug Saf 2013;8:357-63.

36. Colmers IN, Bowker SL, Majumdar SR, et al. Use of thiazolidinediones and the risk of bladder cancer among people with type 2 diabetes: a meta-analysis. CMAJ 2012;184:E675-83.

37. Ferwana M, Firwana B, Hasan R, et al. Pioglitazone and risk of bladder cancer: a meta-analysis of controlled studies. Diabet Med 2013;30:1026-32.

38. de Vries F, Zeegers MP, Knapen LM, et al. Thiazolodinediones and cancer: duplicate publication bias? Oncologist 2013;18:1147.

39. de Vries F, Goossens ME, Zeegers MP. Pioglitazone and bladder cancer: two studies, same database, two answers. $\mathrm{Br} J$ Clin Pharmacol 2013;76:484-5.

40. Bazelier MT, de Vries F, Vestergaard P, et al. Use of thiazolidinediones and risk of bladder cancer: disease or drugs? Curr Drug Saf 2013;8:364-70. 